\title{
Accidental Intraoral Formalin Injection as Local Anesthetic Agent in an Outreach Activity: A Rare Case Report
}

\author{
Sauvik Singha*1, Hemasha Daryani ${ }^{2}$, Kshitij Aggarwal ${ }^{3}$, Anshalika Agrawal $^{4}$ and Jugajyoti Pathi ${ }^{5}$ \\ 1,3,4 PG Resident, Department of Oral and Maxillofacial Surgery, Hitkarini Dental College and Hospital \\ ${ }^{2}$ Reader, Department of Public Health Dentistry, Hitkarini Dental College And Hospital \\ ${ }^{5}$ Senior Lecturer Department of Oral and Maxillofacial Surgery, Kalinga Institute of Dental Sciences
}

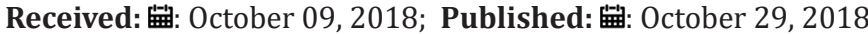

*Corresponding author: Sauvik Singha, Bhubaneswar Multispeciality Dental Clinic, RCMS Complex, Press chawk, Gajapatinagar, Bhubaneswar 751005

\section{Introduction}

$35-40 \%$ aqueous solution of formaldehyde is termed as formalin [1]. It is a toxic substance which upon exposure to skin and mucosa creates first degree and second-degree burn [2]. Simultaneously it has deleterious effect on gastrointestinal and respiratory system [3]. It can be fatal too in a dose of 50-100ml in the $40 \%$ concentration [4].

\section{Case Report}

We are reporting the first case of inadvertent injection of formalin mistaken as local anaesthetic agent in a rural camp setup. On the fine morning of Doctors' day, the authors were invited in a dental treatment camp in a remote village where the very first patient came with the chief complaint of mobility of anterior tooth. On clinical examination the lower right central incisor was Glickman's Grade II mobile and advised for extraction. Patient was in good physical and mental state. The case was assigned to a freshly passed out graduate. After pre-surgical accepted procedure, the doctor in-charge infiltrated local anaesthetic solution. Within couple of minutes patient started complaining of sharp burning pain sensation and severe discomfort on the injection site associated with headache and breathlessness. The procedure was stopped, and the authors were called immediately. Authors examined the local anaesthetic vial for expiry date and found that the seal was broken, and no tag was applied on the bottle regarding the content. The original local anesthetic agent tag was intact on the vial. After opening the rubber cup, it was found that the vial thought of containing local anaesthetic agent was actually pungent smelling clear liquid that is formalin. Mistakenly the assistant (provided by the camp organizer) loaded formalin solution $2 \mathrm{ml}$ from a preemptied anaesthetic bottle which was kept there to collect biopsy specimens. There was a crowd of more than 200, so one of the authors was taking care of the mob and explaining, other took the patient to nearby pharmacy which was 12 kilometres far.

\section{Treatment}

a) Saline was injected at the injection site to dilute the formalin.

b) Intramuscular Dexamethasone 8mg twice with tapering for 5 days given to reduce the inflammation and to counteract sudden respiratory embarrassment

c) Intravenous slow Pheniramine $10 \mathrm{ml}$ twice for 5 days given as an anti-allergic

d) Intramuscular Diclofenac sodium twice for 5 days for pain

e) Intravenous Amoxicillin + Clavulanate 1.2 gm to reduce the chance of aerobic infection, especially gram-positive bacteria's

f) Intravenous Metrogyl $100 \mathrm{ml}$ thrice for 5 days prophylactically given to counteract anaerobic infection

g) Intravenous Ranitidine $2 \mathrm{cc}$ for 5 days for to prevent gastric upset

h) Tab Phlogam thrice for 5 days to reduce swelling

i) Hydrogen peroxide mouthwash and Betadine mouthwash alternatively [5]

Patient was shifted to local primary health centre for monitoring of vital signs. Next Day increasing edema, erythema of face was suggestive of chemical cellulites (Figure 1). Recalled on SOS or after 7 days (Figure 1) (Figure 2). Telephonic consultation was made in between with the PHC incharge and at the end of the week patient 
was asymptomatic with necrotic sloughing on the floor of the mouth. We reviewed the patient in an interval of a week and at the end of 2 months he was completely recovered (Figure 3 ).

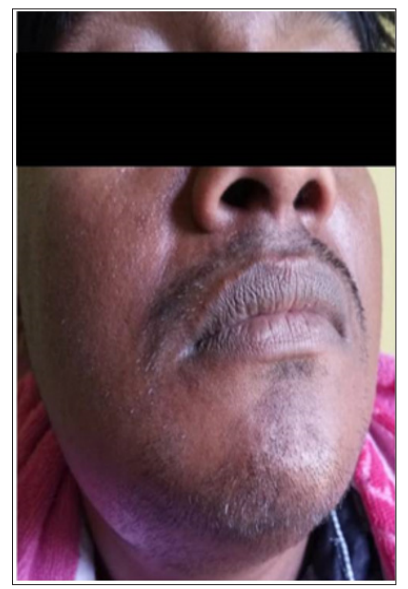

Figure 1: Extraoral Photograph on $7^{\text {th }}$ day.

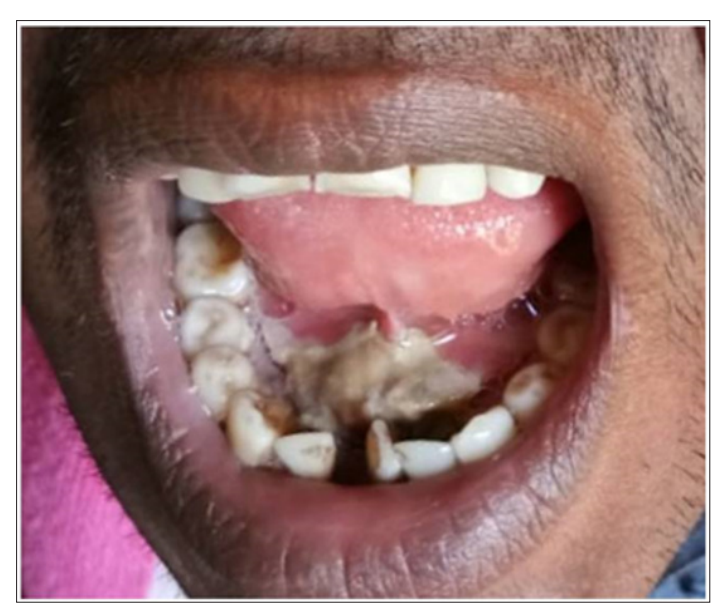

Figure 2: Intraoral photograph on $7^{\text {th }}$ day.

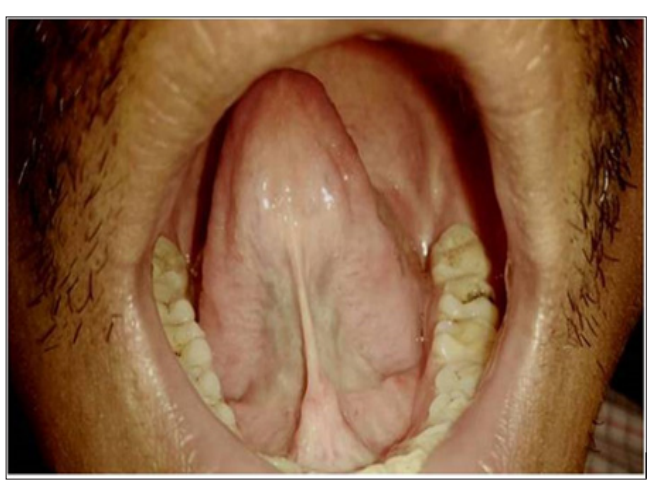

Figure 3: 2months Follow up.

\section{Discussion and Conclusion}

In Dentistry there are many clear solutions sodium hypochlorite, normal saline, local anaesthesia, hydrogen peroxide and formalin used for different purposes. They all require special storage and handling [6] In our case report mishap happened due to the negligence of the supporting staff (provided by the organisers) but as the amount was low patient survived without any systemic complications. Root cause are firstly, we don't use single use cartridges, for economic reasons. In India most of the practitioners use multi use vials.1 Secondly, we also reuse local anaesthetic solution vial to store other solutions and when the refilled solution is clear then confusion happens, if at all we are reusing the vial, it should be well tagged about the content. Thirdly, keeping the solution not used for injection should not be there in the core clinical area and finally, employing untrained staff as an assistant should not be done because a small mistake from your assistant can create a great trouble to you. We should stick to these rules in practice as well as in camp and specially the rural ones because the value of life is same [7].

\section{References}

1. Gupta DS, Srivastava S, Tandon PN, Jurel S, Sharma S, et al. (2011) Formalin induced iatrogenic cellulitis: A rare case of dental negligence. J Oral Maxillofac Surg 69(12): 525-527.

2. VK Tiwari (2012) Burn wound: How it differs from other wounds? Indian J Plast Surg 45(2): 364-373.

3. Rajan N, Rahim R, Krishna KS (1985) Formic acid poisoning with suicidal intent: a report of 53 cases. Postgrad Med J 61(711): 35-36.

4. Pun KK, Yeung CK, Chan TK (1984) Acute intravascular hemolysis due to accidental formalin intoxication during hemodialysis. Clin Nephrol 21(3): 188-190.

5. Sarode SC, Sarode GS, Ingale Y, Ingale M, Chavan M, et al. (2018) Accidental local infiltration of formalin intothe buccal mucosa: A case report and review of the literature. S Clin Pract 8(1): 1040.

6. Dandriyal R, Giri KY, Alam S, Singh AP (2014) Accidental intraoral formalin injection: a rare case report. Clin Pract 4(3): 686.

7. Arakeri G, Brennan PA (2012) Inadvertent injection of formalin mistaken for local anesthetic agent: report of a case. Oral Surg Oral Med Oral Pathol Oral Radiol 113(5): 581-582. 


\section{ISSN: 2574-1241}

DOI: 10.26717/BJSTR.2018.10.001961

Sauvik Singha. Biomed J Sci \& Tech Res

CC (i) This work is licensed under Creative

Commons Attribution 4.0 License

Submission Link: https://biomedres.us/submit-manuscript.php

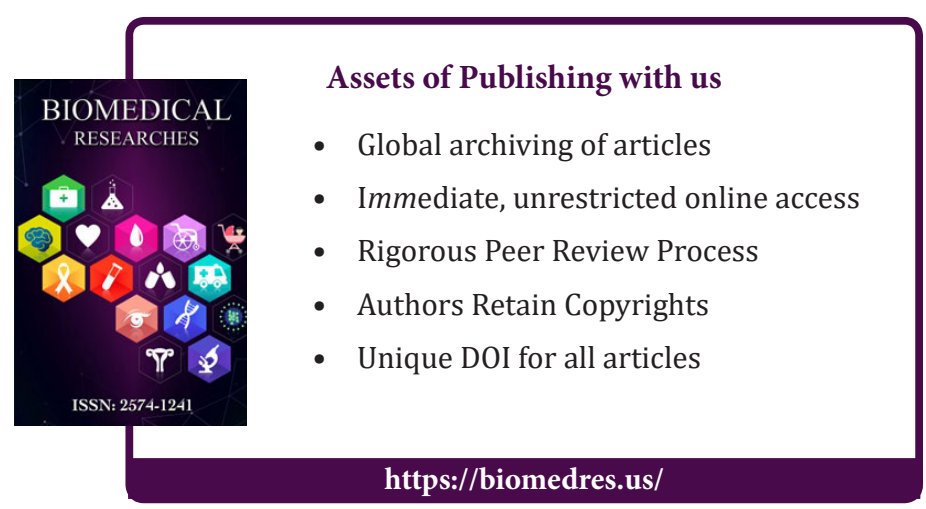

